\title{
Faculty versus Administration A Universal Problem
}

\section{Lionel S. Lewis and Philip G. Altbach}

Lionel S. Lewis is professor of sociology at the State University of New York at Buffalo. Philip G. Altbach is professor of higher education and director of the Center for International Higher Education at Barton College. He is a senior associate of the Carnegie Foundation for the Advancement of Teaching.

$\mathrm{W}$ ith the premise of a modicum of facultyloyalty and participation, colleges and universities can be likened to extended families. Indeed, the university is commonly described as being a "community of scholars." Generally, faculty play a key role in governing their college or university, and make major decisions concerning the curriculum, the content of courses, degree requirements, and the like. In some countries, faculty elect top administrative officers, and in many places they have a significant influence on the appointment of senior administrators-deans, presidents, vice chancellors and rectors. Yet, faculty are everywhere deeply alienated from the top administration of their collegesand universities. This dilemma has profound implications for the future of higher education. It is especially crucial in a period of fiscal constraint and of great pressure on academicinstitutions for change.

The Carnegie International Survey of the Academic Profession, which studied academicsin 14 countries, found nearly universal and significant alienation of faculty from administrators. There were only minor variations among the countries participating in the survey (the United States; England, Germany, the Netherlands, Russia, and Sweden in Europe; Hong Kong, Japan, and South Korea in Asia; Brazil, Chile, and Mexico in Latin America; Israel in the Middle East; and Australia). Japan is the only country in which a majority of faculty feel that top administrators provide competent leadership. The 1991-93 survey was the first ever conducted internationally, and this nearly universal lack of regard by faculty for administrators is one of the most significant findings.

We found the miasma of distrust and alienation from administration especially surprising because academics are, in general, fairly satisfied with their careers despite the nearly universally difficult circumstancesof higher education. Academics were not reluctant to express dissatisfaction with elements of contemporary academic life. Except in Hong Kong, they are extremely unhappy with their remuneration. In five countries - Chile, Israel, Ko- rea, Mexico, and Russia - a majority rate their salary as poor, and only in two countries - Hong Kong and the Netherlands-do a majority rate salaries as excellent or good. Many also feel that they are under too much pressure, and they find their professional life a source of strain. Nonetheless, when asked if they would choose an academic career again, a large majority in all countries responded affirmatively. Given the problems facing higher education worldwide, and the erosion of academic salaries in so many countries, the academic profession is remarkably content. They are particularly satisfied with the courses they teach and the autonomy academic life gives them to pursue their intellectual interests. Although the professoriate around the world may express discontent about a number of issues, it clearlyhas not lost sight of the positive aspects of academic life.

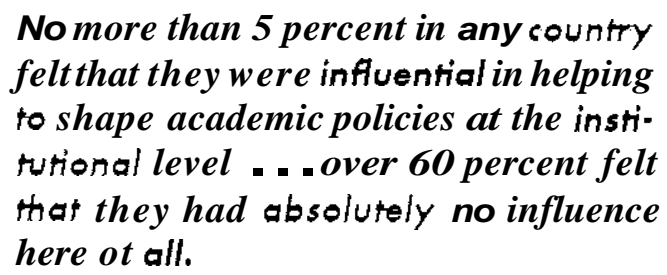
felt that they were influential in helping to shape academic policies at the institutional level ... over 60 percent felt that they had absolutely no influence here ot all.

Academics are happy with their jobs and with their careers, hut they are extremely unhappy with their institutions. The root of this, they say, is poor leadership. Academic institutions are not succeeding in large part because administrators are squandering too much of their resources on themselves and ill-conceived misadventures. It would seem that, not only in the United States but around the world, many academics are of the opinion that a greater proportion of diminishing budgets should go to purely academic functions. Faculty express strong loyalty to their disciplines and fields of study, but they have significantlyless commitment to their own colleges and universities.

There are, of course, a variety of other reasons why academics have less loyalty to their institutions. There is a widespread commitment to research as an ideal, and research-minded faculty are traditionally less focused on institutional matters than are their more teaching oriented counterparts. But there are too many faculty whose outlook is local rather than cosmopolitan who indicate a strong 
antipathy toward administrators to suggest that there is not more involved here.

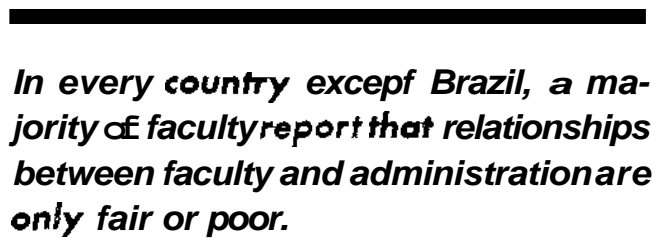

The survey asked scholars and scientists to reflect on issues of institutional governance, and common concerns emerged. Respondents, when asked ahout institutional centralization and decentralization, report that there is a disturbing trend when it comes to most of the major elements of decision making. Since World War II, as higher education rapidly expanded, the close, more collegial and informal patterns of decisionmaking have to some extent seemed less effective, and a large proportion of the respondents are aware and concerned about the trend toward the growing bureaucratization in higher education. They are unhappy and unsure how to cope with the more hierarchical, more rigid governance structure. As a result, faculty dissatisfaction with current administrative and governance arrangements is high. In every country except Brazil, a majority of faculty report that relationships between faculty and administration are only fair or poor. In no country do more than 9 percent describe these relations as excellent. In fact, in a majority of countries fewer than 5 percent believe that they are excellent. Senior faculty are more sympathetic toward administrators than are junior faculty, who have more questions about the competence and goodwill of those who manage institutions of higher learning. An almost equal percentage of senior and junior faculty are completely disillusioned and pessimistic. Not surprisingly, many believe that they have most influence on decision making in their academic department or similar unit, with majorities in almost all countries feeling that they are either very influential or somewhat influential at this level. Respondents in Germany and Mexico are least likely to express this view.

No more than 5 percent in any country feel that they are influential in helping to shape academic policies at the institutional level. Most who believe this are senior faculty with many years of service to their institution. In eight countries - Australia, Chile, England, Germany, Hong Kong, Mexico, Sweden, and the United States-over 60 percent feel that they have absolutely no influence here at all. The considerable alienation from the higher echelons of administration at their institutions that scholars and sci- entists around the world feel is unqualified. An unusually large number express complete dissatisfaction with and doubts ahout the quality of the leadership provided by toplevel administrators at their colleges and universities; they do not believe much can he done to alter the fractious relationships between faculty and administrators. In nine comtries, a smaller percent agree than disagree that top-level administrators are providing competent leadership. The distrust is pervasive. Less than half are convinced that they are informed ahout what is going on, and close to half characterize communication between the faculty and the administration as poor.

In eight countries, the majority of faculty report that academic administrators are autocratic; respondents in Australia, England, Germany, and Hong Kong are most likely to agree with this statement. In six countries, a majority agree that a lack of faculty involvement in governance is a problem. Only in the United States and Japan do more than half of the faculty feel that administrators even support academic freedom. Other questions elicit a general dissatisfaction with how their campus is managed on the part of faculty.

\section{Surely, the financial setbacks higher education has $f$ a din recent years have contributed to faculty unrest.}

Surely, the financial setbacks higher education has faced in recent years have contributed to faculty unrest. Yet, this does not vitiate the fact that there is a need to create new mechanisms to bring faculty and administrators together to resolve problems, reestablish communications, and renew collegialityso that in the end mutual trust and respect are fostered and restored. Paradoxically, however, very few faculty express an interest in taking on more administrativeresponsibilities. They see such chores as interfering with their teaching and professionalcommitments. They vociferously complain ahout not being involved, but consistently reject opportunities to have greater influence on campus affairs.

It will not be an easy matter to rectify the pervasive ill will in academia. There is ample evidence that campus working conditions are deteriorating in most of the countries included in the Carnegie survey. Only in East Asia do objective circumstances seem fairly stable in terms of workload, salary, and the overall situation on campus, although in Japan and Korea economic slowdown and changing demographics are negatively affecting academe. 
Generally, classes are getting larger, there is pressure for academics to teach more, funds available for research are declining, and salaries are not keeping abreast of inflation. There are signs that the morale of the academic profession is beginning to be sapped. Academic administrators, who must say "no" more often, are obvious and easy targets for those who feel exploited and unappreciated.

The decline of institutional commitment is of great significance as universities struggle to change in order to meet new demands and shoulder the burdens imposed by fiscal problems and government-imposed legislation. Traditionally, colleges and universities have depended on the faculty to implement policy, and for decades the faculty has also played a central role in formulating policies as well. The hallowed concept of institutional autonomy, perhaps honored in most countries more in ideology than in reality, has come under increasing attack as governments have moved to reduce expenditure on higher education and to centralize decision making. Many faculty believe that the calls for accountability are politically motivated, and that they are simplybeing scapegoated. Large numbers are feeling that the harder they try, the less they are appreciated.

Universities worldwide face a dilemma. There is a near universal trend toward more emphasis on teaching, demands that faculty members account for their activities, with assessment as a means of measuring the effectiveness of academic effort, and a growing societal unease with traditional ideas of university autonomy. These trends have gone furthest, perhaps, in England, where our surveymakes it more transparent that faculty morale has plummeted, and alienation is widespread.

But there is extensive evidence of this pressure everywhere. If ever there was a "golden age" for the professoriate, it has obviously passed. Academic institutions are increasingly seen by policymakers and opinion leaders as large enterprises that should be managed by the same criteria applied to other sectors of the economy. Our analysis shows that the core of the university, the faculty, do not feel comfortable with this view. As a result, they are increasingly alienated from their institutions. The majority of faculty in every country surveyed, except the Netherlands, felt that the sense of community was declining on campus.

Happily, faculty members still have a commitment to their profession and to the role of teacher and researcher. On the other hand, they have serious skepticism about current trends in higher education; an alarming number feel victimized. If the academic profession remains alienated from institutional leadership and from current changes in higher education worldwide, it is unlikely that higher education will move into the 21 st century on a positive note.

\section{The Ratchet and the Lattice}

\section{Understanding the Complexity of the Modern University}

\section{Peter Nichols}

Peter Nichols is a staff writer for the University of Pennsylvania's Institute for Reseoch on Higher Education.

Editor's Note: This article was adapted by Peter Nichols from the June 1990 issue of Policy Perspectives. While the article focuses on the United States, it has relevance internationally, and for this reason we are indebted to Peter Nichols for his assistance. The concept was developed by Profesor William F. Massy, director of the Stanford Research Institute on Higher Education, Stanford University.

I ncreasingly, colleges and universities are being asked to change the way they conduct their business: how decisions are made, how functions are staffed, how buildings are built and with what amenities, and finally, how the energies of the institution are distributed between collective goals and individual pursuits. How can colleges and universities redesign the way they conduct their business without sacrificing their ability to invest in new ideas? A first step in answering this question is to gain a more particular understanding of how and why institutional costs have increased over the last decade. Two images that provide an insight into these changes are what the Pew Higher Education Roundtable has termed the "administrative lattice" and the "academic ratchet." It is the combined actions of the lattice and the ratchet that increase institutional costs. The insights for these ideas come from the American higher education system, hut there is considerable international relevance.

\section{The Lattice}

The administrative lattice describes the proliferation and entrenchment of administrative staff at American colleges and universities over the past two decades. The term connotes not just the fact of this increase in staff-estimated at 60 percent nationwide between 1975 and 1985 - but its effects on an institution's operations and costs. These include the transfer of tasksformerly accorded to faculty; the growth of "consensus management," which effectively diffuses risk and responsibility for decisions; and the increase of costs and decline of efficiency as administrative bureaucracy extends and solidifies its ties within an institution. The impulse at almost every turn has been to develop the lattice 